NBER WORKING PAPER SERIES

\title{
HOW ARE SMALL BUSINESSES ADJUSTING TO COVID-19? EARLY EVIDENCE FROM A SURVEY
}

\author{
Alexander W. Bartik \\ Marianne Bertrand \\ Zoë B. Cullen \\ Edward L. Glaeser \\ Michael Luca \\ Christopher T. Stanton \\ Working Paper 26989 \\ http://www.nber.org/papers/w26989 \\ NATIONAL BUREAU OF ECONOMIC RESEARCH \\ 1050 Massachusetts Avenue \\ Cambridge, MA 02138 \\ April 2020
}

We thank Karen Mills for connecting us to the leaders at Alignable and to Eric Groves, Venkat Krishnamurthy, and Geoff Cramer for help in facilitating survey distribution. Dylan Balla-Elliott, Manal Saleh, and Pratyush Tiwari provided excellent research assistance. We received no external funding for this research. The views expressed herein are those of the authors and do not necessarily reflect the views of the National Bureau of Economic Research.

At least one co-author has disclosed a financial relationship of potential relevance for this research. Further information is available online at http://www.nber.org/papers/w26989.ack

NBER working papers are circulated for discussion and comment purposes. They have not been peer-reviewed or been subject to the review by the NBER Board of Directors that accompanies official NBER publications.

(C) 2020 by Alexander W. Bartik, Marianne Bertrand, Zoë B. Cullen, Edward L. Glaeser, Michael Luca, and Christopher T. Stanton. All rights reserved. Short sections of text, not to exceed two paragraphs, may be quoted without explicit permission provided that full credit, including ( $)$ notice, is given to the source. 
How Are Small Businesses Adjusting to COVID-19? Early Evidence from a Survey

Alexander W. Bartik, Marianne Bertrand, Zoë B. Cullen, Edward L. Glaeser, Michael Luca, and Christopher T. Stanton

NBER Working Paper No. 26989

April 2020

JEL No. E65,I12,L20

\section{$\underline{\text { ABSTRACT }}$}

In addition to its impact on public health, COVID-19 has had a major impact on the economy. To shed light on how COVID-19 is affecting small businesses - and on the likely impact of the recent stimulus bill, we conducted a survey of more than 5,800 small businesses. Several main themes emerge from the results. First, mass layoffs and closures have already occurred. In our sample, 43 percent of businesses are temporarily closed, and businesses have - on average reduced their employee counts by 40 percent relative to January. Second, consistent with previous literature, we find that many small businesses are financially fragile. For example, the median business has more than $\$ 10,000$ in monthly expenses and less than one month of cash on hand. Third, businesses have widely varying beliefs about the likely duration of COVID related disruptions. Fourth, the majority of businesses planned to seek funding through the CARES act. However, many anticipated problems with accessing the aid, such as bureaucratic hassles and difficulties establishing eligibility.

Alexander W. Bartik

University of Illinois

1407 W. Gregory Road

214 David Kinley Hall

Urbana, IL 61821

abartik@illinois.edu

Marianne Bertrand

Booth School of Business University

of Chicago

5807 South Woodlawn Avenue

Chicago, IL 60637

and NBER

marianne.bertrand@chicagobooth.edu

Zoë B. Cullen

Rock Center 210

Harvard Business School

60 N. Harvard

Boston, MA 02163

zcullen@hbs.edu
Edward L. Glaeser

Department of Economics

315A Littauer Center

Harvard University

Cambridge, MA 02138

and NBER

eglaeser@harvard.edu

Michael Luca

Harvard Business School

Soldiers Field

Boston, MA 02163

and NBER

mluca@hbs.edu

Christopher T. Stanton

210 Rock Center

Harvard University

Harvard Business School

Boston, MA 02163

and NBER

christopher.t.stanton@gmail.com 


\section{Introduction}

How are America's small businesses navigating the economic disruptions resulting from COVID-19, and how will the CARES Act affect their decisions and future prospects? To explore these questions, we conducted a survey of more than 5,800 small businesses that were members of the Alignable business network. The survey focused on assessing (1) the current level of financial fragility among small businesses, (2) the extent to which small businesses have already temporarily closed and laid off employees, (3) expectations about how long the crisis will last and how this is affecting business decisions, and (4) decisions about whether to seek funding through the CARES Act, and how this will impact layoff and closure decisions. In this short note, we present the survey results and themes that emerge.

Overall, our results suggest that the pandemic has already caused massive dislocation among small businesses. While businesses' beliefs about the duration of the crisis vary widely, the median business owner expects the dislocation to last well into mid-summer. Businesses are adjusting in a variety of ways, and over seventy percent of respondents anticipate taking advantage of aid when asked about a program that resembles the Paycheck Protection Program (PPP) that is part of the CARES act. Moreover, they expect this funding to influence other business decisions - including layoff decisions and staying in business altogether. At the same time, many businesses were reluctant to apply for funding through the CARES Act because of concerns about administrative complexity and eligibility.

This note proceeds as follows. Section 2 discusses the survey design. Section 3 discusses the characteristics of the firms that responded to the survey and their representativeness. Our survey was conducted through Alignable, a network of 4.6 million small businesses, and was included as a link in a March 26, 2020 email to their members. We received 7,511 responses during the first week, which represents approximately one-tenth of Alignable's members who responded to a quick reaction one or two question survey distributed around the same time. After restricting to firm owners located in the United States, we are left with 5,819 responses. The size distribution of the firms in our sample roughly matches the size distribution of firms in the 2017 Census of US Businesses with fewer than 500 employees. The geographic spread looks similar to the spread across the United States, although California is somewhat over represented. Our sample is likely to be disproportionately technology savvy because it is drawn from the ranks of 
members of a digital business network. The voluntary nature of the survey may also have attracted businesses that experienced a greater impact of COVID-19.

In Section 4, we explore the current and expected impacts of COVID-19 on these businesses. Three themes emerge in this section. First, our results suggest disruptions have already been extreme. Across the sample as a whole, 43 percent of businesses have temporarily closed and nearly all of these closures are due to COVID. This response seems far more extreme than the economic effects of the 1918 inluenza epidemic found by Barro, Ursua and Weng (2020) and Garrett (2007, 2008). Respondents that have closed temporarily largely point to reductions in demand and employee health concerns. Disruptions in the supply chain have been less of a concern so far. On average, the businesses report having reduced their employees by 40 percent since January. The decline is particularly sharp in the Mid-Atlantic region (which includes New York City), where 54 percent of firms are closed and employment is down by 47 percent. Impacts also vary across industries, with retail, arts and entertainment, personal services, food services, and hospitality businesses all reporting employment declines exceeding 50 percent. Finance, professional services, and real estate related businesses have seen less disruption.

Second, our results suggest that many businesses are financially fragile. The median firm with expenses over $\$ 10,000$ per month has only enough cash on hand to last for two weeks. Three-quarters of respondents state that they only have enough cash on hand to cover two months of expenses or less. Parsa et al. (2005) also note the fragility of small restaurants. Firms with more cash on hand are relatively more optimistic that they will remain open at the end of the year. Third, beliefs about the likely duration of the crisis vary widely. Fifty percent of respondents believe that the crisis will last at least until the middle of June, suggesting that many businesses expect this to extend well beyond their current cash.

In Section 5, we present results from a module of the survey that experimentally varies policy proposals, allowing us to explore responses to policies such as the recently passed CARES Act. The firms' limited cash on hand suggests that there will be robust demand for Federally-subsidized aid or business loans. Indeed, more than seventy percent of the respondents expressed interest in a hypothetical program with features resembling the PPP aid. Yet a large number of respondents also anticipated problems with accessing the aid, citing issues such as bureaucratic hassles and difficulties establishing eligibility. Part of this module also allows a 
counterfactual evaluation of a straight loan policy, which is a stylized representation of traditional SBA disaster relief programs. While the more generous CARES Act does improve take-up and business outcomes, traditional loans with speedy delivery and sufficient liquidity are also found to meaningfully shift business owners' expectations about survival even in the face of lower take-up rates.

Section 6 considers survival rate differences across industries, and how this depends on the duration of the crisis. In-person industries like personal services or retail report much lower prospects for riding out the pandemic than professional services or other sectors with minimal need for face-to-face contact. Unsurprisingly, the longer the crisis last, the lower the probability that firms ascribe to their reopening after the crisis. If the crisis lasts 4 months instead of 1 month, only $47 \%$ of businesses expect to be open in December compared to $72 \%$ under the shorter duration.

Section 7 concludes. The COVID-19 crisis represents a once-in-a-generation crisis for America's small businesses, especially those that specialize in face-to-face service. One fifth of America's workers labor in retail trade, leisure and hospitality and these sectors are particularly vulnerable to the current pandemic.

There is little precedent for the ongoing economic disruptions resulting from the COVID19 crisis. Our survey documents the enormous disruption that is already occurring and the limited financial resources that small businesses have to weather this storm. Our results suggest that the implementation details of the CARES Act loans are likely to play an important role in ensuring the medium-term solvency of small businesses. The impact of the CARES Act is also likely to depend on the extent to which lenders prioritize simplicity of the sign-up process, transparency of eligibility and repayment rules, and speed of accessing cash.

\section{Survey Design and Details}

Our survey was sent out in partnership with Alignable, which is a network-based platform focused on the small business ecosystem. Alignable enables businesses to share knowledge and interact with one another, and currently has a network of 4.6 million small businesses across North America. Much of the network growth has been organic, with little outside marketing. 
Alignable also regularly sends out polls (which they call "pulse surveys") to users. At the end of a regular pulse-survey, participants who took that poll received an email inviting them to participate in a more comprehensive survey being conducted by researchers at Harvard Business School. Appendix 1 shows the message seen by respondents who clicked on the link. Participants were shown a disclosure statement and consent protocol. No payments were offered; participation was completely voluntary.

We received 7,511 responses within the first week. 5,819 of these can be traced back to U.S. based businesses, which is the relevant sample for understanding policy. While the 7,511 responses represents a small fraction (.017 percent) of Alignable's total membership, it represents a much larger share of Alignable's membership that has engaged with their weekly pulse surveys on COVID-19. Alignable estimates that 50,000-70,000 members are taking these pulse surveys weekly, which suggests a 10 - 15 percent conversion rate relative to these more active respondents.

Our sample, therefore, is selected in three ways: (1) they are firms that have chosen to join Alignable, (2) they are Alignable firms that have chosen to stay actively engaged taking surveys, and (3) they are the set of firms that are active within Alignable that chose to answer our survey. Consequently, there are many reasons to be cautious when extrapolating to the entire universe of America's small businesses. We will discuss their representativeness based on observable attributes in the next section of this report.

The survey included a total of 43 questions, with basic information about firm characteristics (including firm-size and industry), questions about the current response to the COVID-19 crisis, and beliefs about the future course of the crisis. Some questions were only displayed based on skip logic, so most participants responded to fewer questions. The survey also includes an experimental module that randomized between respondents to understand how different federal policies might impact these firms' behavior and survival as the crisis unfolds. Specifically, we experimentally varied some of the descriptions of potential policies across the sample to shed light on the potential impact of different policies. We will discuss that module more thoroughly in Section V. A further experimental module included between-respondent randomization exploring decisions under different hypothetical durations of the crisis.

\section{Firm Characteristics and Representativeness}


The survey contains three baseline questions which enable us to assess the representativeness of the sample along observable dimensions: number of employees, typical expenses (as of January 31, 2020), and share of expenses that go towards payroll. We are also able to get rough information about geolocation to asses representativeness by state.

We compare our data with data on businesses from the 2017 Census of US Businesses, using the publicly available statistics published by the US Census Bureau. The underlying data is drawn from the County Business Patterns sampling frame and covers establishments with paid employees, including sole-proprietorships. The Census data captures large and small businesses alike, but for our comparisons, we will look only at businesses with fewer than 500 employees.

The Alignable network allows users to share customer leads, which could potentially skew our sample towards retail and service businesses that interact directly with consumers. As retail businesses are particularly vulnerable to COVID-19 disruptions, that could lead our sample to overstate the aggregate dislocation created by the crisis. However, as we discuss later, our data on industry mix suggests that the sample does represent a wide swath of America's smaller businesses. Naturally, industries dominated by large firms, such as manufacturing, are underrepresented.

Figure 1 shows the size distribution of our sample and the size distribution of businesses with fewer than 500 employees in the Economic Census. The match of employment sizes is reassuring. About 64 percent of the businesses in our sample have fewer than five employees, while about 60 percent of the firms in the Economic Census are that small. About 18 percent of businesses in both samples have between 5 and 9 employees. The survey becomes less well matched to the Census among the larger employment groupings, and we believe that our survey will capture the experience of larger employers with less accuracy.

While our survey does not allow for an apples-to-apples comparison of payroll expenses with Census data, we constructed a rough comparison by approximating payroll expenses for the Alignable firms from categorical questions about monthly expenses and the share of these expenses going toward payroll. The Census provides annual payroll expenses for W2 employees. To get a sense of the match, we compared our estimated monthly payroll expenses in our sample with one-twelfth of annual expenses in the U.S. Census. To facilitate comparison, we divide by 
an estimate of total employment. ${ }^{2}$ Figure 2 shows the size distribution of monthly estimated payroll expenses in our sample and a comparable breakdown for the Census using a per-capita adjustment. The match is imperfect, especially for larger firms. The discrepancy might reflect the under-representation of manufacturing or professional services firms in our sample, which are among the highest paying of all 2 digit NAICS sectors in the Census data. Appendix Table 1 provides further detail on the industry match to the Census.

Figure 3 shows the geographic scope of our sample. The Alignable sample draws particularly from California, the New York region, Florida, and Texas. The sample is notably sparse in America's western heartland. That distribution is qualitatively similar to the distribution of smaller businesses in the Economic Census.

Figure 4 shows the share of our sample coming the 10 most populous states. The figure also includes the share of small establishments in the Economic Census that are within each state. For example, California has 14.4 percent of our Alignable survey sample, 12.5 percent of small businesses in the Census data and 11.52 percent of total U.S. population. Our sample does overrepresent the coasts and underrepresents Illinois.

Overall, while the sample captured by the survey has limitations and may not be an imperfect snapshot for certain pockets of America's small businesses, the sample allows for important insight into the overall small business ecosystem. The sample is large and includes firms from most major industry groups, states, and firm-size categories.

\section{Responses to the COVID-19 Pandemic and Lockdown}

We now turn to our main results, which we group into three categories. First, we describe the current impact of COVID-19 on business operations and employment. Second, we report our results on the financial fragility of those businesses, as captured by their cash on hand and ongoing expenses. Third, we turn to their expectations about the duration of the crisis and their own economic survival.

Temporary Closings and Employment

We begin by asking owners whether their business is currently operational. We allowed owners to respond that the business was operational, temporarily closed, or permanently closed.

\footnotetext{
${ }^{2}$ This comparison is very likely to include different "headcount" as we do not disambiguate between W2 and 1099 employment in the survey.
} 
We also allowed them to report whether the business was closed because of COVID-19 or because of some other reason. ${ }^{3}$

Across the sample, 41.4 percent of businesses reported that they were temporarily closed because of COVID-19. A far smaller number - 1.8 percent - reported that they were permanently closed because of the pandemic. By contrast, only 1.3 percent reported that they were temporarily closed for other reasons. 55.4 percent report that they were still operational.

We also asked the businesses owners to fill in a matrix that contained the number of both full time and part time employees that were employed by the firm now and as of January 31 , 2020. Over the entire sample, the number of full-time employees had fallen by 32 percent. The number of part-time employees was 56 percent lower than it had been at the end of January. These results include businesses that have temporarily closed. If we look only at businesses that are still operating, we find that the number of total fulltime employees has fallen by 17.5 percent. The number of part-time employees has declined by 36 percent. Overall employment has declined significantly, totaling only $60 \%$ of January headcount.

Table 1 shows our results across the eleven Census Division and displays the share of businesses that had temporarily closed because of COVID-19 and the reduction in total employment between January 31 and today. The results are not meaningfully different if we separate out full time or part time employees. While there is regional heterogeneity, the picture is fairly bleak almost everywhere.

The Mid-Atlantic division has the sharpest decreases in employment and the largest share of firms that have temporarily suspended operations. Fifty-four percent of firms in that region are now closed, and employment has fallen by an average of 47 percent. The Mountain region is the least effected, but even there 39 percent of firms have temporarily closed and employment has declined by 32 percent.

Tables 2 and 3 display the same breakdown by firm size and industry. Smaller firms with fewer than 20 employees in January are more likely to be closed. Firms with between 6 and 19 January employees have the largest employment reductions. Across industries, in-person retail

\footnotetext{
${ }^{3}$ We did not attempt to assess the quality of firm management, as in Bloom et al. (2013). We hope that future surveys will test when quality of management helps protect firms against closure during this crisis. This crisis also presents an opportunity to understanding managerial decision-making under stress, as discussed by Bazerman and Moore (1994).
} 
and services businesses have declined precipitously. Although hard hit, the impact is not as extreme for professional services firms, banking and finance, real estate, or construction.

Table 4 shows the problems that firms are facing by their current operational status. We asked owners to rate on a 1 to 100 scale the problems that they are having with employee illness, supply chains and customer demand. The scale had both numerical values, and also a text label that went from "Not a concern" at one end to "Extremely disruptive" at the other end. We differentiate between firms that are open, temporarily closed and permanently closed, and we show the share of firms in each category that indicate significant difficulties in each of these areas.

On average, firms rated the disruptions resulting from supply chain challenges to be 35 out of the 100-point scale (which is in the "slightly disruptive" part of the scale). Concerns about employee health were more prominent of a concern, with firms rating it as 57 out of 100 in terms of importance (which maps to "somewhat disruptive"). Reductions in demand were even more disruptive, with firms rating the importance of this to be 78 out of 100 (extremely disruptive). While closed firms noted worse disruptions due to demand, the basic ranking of the problem areas was consistent across types of firms. This suggests that supply chain problems have thus far been less pronounced, relative to disruptions resulting from demand shocks and concerns about employee health.

Altogether, these results suggest that a vast number of enterprises have temporarily shut down and laid off workers. We now ask whether these firms have the resources to weather the crisis over the months ahead.

\section{Financial Fragility}

To measure financial fragility, we asked the respondents "roughly how much cash (e.g. in savings, checking) do you have access to without seeking further loans or money from family or friends to pay for your business?" We then divided this amount by their January 31 monthly expenses to understand how long they could maintain operations without seeking extra credit. ${ }^{4}$

\footnotetext{
${ }^{4}$ We did not collect information about access to lines of credit or outside borrowing, but given the severity of the contraction in demand those credit facilities may be unlikely to remain accessible without a government guarantee.
} 
Figure 5 shows a histogram of cash available as a multiple of January 31, 2020 monthly expenses. Approximately one-fourth of firms have cash on hand totaling less than one month's worth of expenses. About one-half of firms have enough cash on hand to cover between one and two months of expenses.

Figure 6 sorts firms by January 31, 2020 monthly expenses and then tabulates the mean and median cash on hand relative to pre-crisis expenses. The median firm with under $\$ 10,000$ in monthly expenses has one month of cash on hand. For all higher spending level, the median firm typically has less than 15 days of cash based on their pre-crisis expense levels. These firms just do not have cash on hand to meet their regular expenses.

These limited levels of cash on hand readily explain why layoffs and shutdowns have been so prevalent. Absent these actions, it is hard to understand how these firms could have met payroll. Moreover, it is hard to imagine how the firms that are still open are going to survive without laying off their existing workers, at least without an infusion of more credit.

\section{Predicting the Path of the Crisis}

Finally, we ask the firms to predict how long the COVID-19 crisis will last and whether they will be open again at the end of 2020. To predict the end of the crisis, we asked the survey respondents what was "the most likely date" when the crisis would be over. We also asked them their confidence about this data on a one to ten scale.

Figure 7 shows the distribution of expected end dates. The figure shows that roughly one-fifth of respondents believe that the crisis will be over by the end of May. Another thirty percent of respondents believe that the crisis will end between the end of May and the start of July. Almost one half of the firms answered that they thought that the crisis would still be going at the start of the July.

However, the firms were not particularly confident about their answers. 50 percent of respondents reported their confidence level as five or less on the one to ten scale. Sixteen percent gave their confidence a two or less. Their uncertainty seems appropriate given the uncertainty that is present throughout the world.

Figure 8 shows the histogram of responses about whether they will be open on December 31, 2020. Overall, more than ninety percent thought it is at least somewhat likely that they would be open. More than 64 percent reported that it is very or extremely likely that they would 
be open-which we later use as a measure of the probability of being open. A growing literature has found entrepreneurs to be overoptimistic about their prospects (see, for example, Bazerman and Moore 1994). This suggests that true survival rates may be even lower.

The firms with more cash on hand were more confident about their future, as evidenced by the split based on whether the firm has more or less cash on hand (relative to usual monthly expenses) than the median in our sample. Forty-nine percent of those firms with more than the median cash on hand thought that it was extremely like that they would be open at the end of the year. Thirty-two percent of firms with less cash on hand than the median thought that they would be open. One interpretation of these fact is that liquidity generates confidence in the ability to survive this crisis. Among firms at least 20 employees, $70 \%$ expressed that they were very or extremely likely to survive, which may indicate greater access to outside resources despite having a higher expense base.

Figure 9 shows the share of firms that think that they are "very likely" or "extremely likely" to be open varies based on their belief about the duration of the crisis. The firms that think that the crisis will be short also believe that they are more likely to survive. Those who believe in a longer crisis are more pessimistic.

\section{Anticipated Responses to CARES Act Programs}

In this section, we discuss the survey's questions about take-up of the CARES Act Paycheck Protection Program (PPP) loans and their expected impact on employment. One important aspect of the CARES program is that "loans that will be fully forgiven when used for payroll costs, interest on mortgages, rent, and utilities," as long as 75 percent of the forgiven amount is spent on payroll and the employer either maintains or quickly rehires workers and maintains salary levels (https://home.treasury.gov/system/files/136/PPP\%20-\%200verview.pdf). Consequently, a significant portion of the "loans" can be seen as a grant rather than traditional debt.

The high level of loan forgiveness means that this represents a large potential transfer to small businesses, and we tried to assess the importance of the grant component of the CARES loans relative to a pure (and far less expensive) loan program. One-third of the survey respondents were randomly asked about their interest in a CARES-like program, which was describe as a loan program which "will be forgiven by the amount spent on payroll, lease, rent, 
mortgage, and utility payments in the 8 weeks after origination." One-third of the respondents were randomly asked about their interest in a loan program that was otherwise identical but without prompting any possibility of forgiveness. ${ }^{5}$ As part of the display, the amount of liquidity was varied, with the caveat to respondents that these policies may not be the actual policies currently available to them. This was designed to measure how program generosity affects take-up and perceived business resilience.

Figure 10 shows the expected take-up of the two programs (and the exact details of the question wording). Seventy-two percent of respondents who were told about the loans with forgiveness said that they would like to take them up. Fifty-nine percent of respondents were interested in taking up the loan program without forgiveness. While there is substantial interest in the credit on its own, there was significantly more interest in the loans with forgiveness.

A primary reason to forgives loans is that such a subsidy might do more to maintain employment and keep businesses open. We therefore re-asked businesses to project their likelihood of being open and their expectations about employment after we told them about the loan programs. Figures 11 and 12 also show the expected probability of being open and the expected employment (relative to January 2020 employment) for the two groups of respondents.

Before they were told about the policies, both groups expected that their employment would be 40 percent lower in December 2020 than it had been in January 2020. After the respondents were told about the CARES-like loans, they projected that their employment would decline by only six percent. The respondents who were told about loans without forgiveness predicted that their employment levels would fall by fourteen percent. We are unable to distinguish precisely whether it is the conditional nature of the PPP program or the more favorable credit terms that drive these differences.

The results when we ask firms about their expectations of remaining in business next December are similar. Before being told about the loans, the businesses thought that they had a

\footnotetext{
${ }^{5}$ Because there was significant policy uncertainty at the time of the survey, one third of respondents were also asked about a potential policy that focused on aid that could only be used for payroll. This policy became less relevant after the details of the CARES act emerged.
} 
62-63 percent chance of being open in December. The probability rose to 81 percent among those who were told about the standard loans. The projected chance of survival increased to 85 percent for the businesses who were informed about the PPP loans that came with forgiveness. Again, the flow of credit seems important, but forgiveness did have a statistically significant impact on the expectation of staying in business.

Why would businesses not take the aid that comes with such generous forgiveness terms? Figure 13 asks the 28 percent of firms that said that they would not take a CARES-like loan why they would turn down such a generous offer. The most common response, given by 35 percent of refusers, is that they did not need the cash, which suggests that one-tenth of our sample truly feels confident with their financial security. ${ }^{6}$

A significant number of those who said that they wouldn't take the CARES assistance cited other concerns. Thirty percent of these respondents said that they didn't think that they would qualify. Nearly twenty percent said that they didn't trust the government to forgive the debt. Over one-tenth thought that it would be too much of a hassle. These results suggest that clarity about the program and a streamlined process will be crucial if the governments wants to ensure a high take-up rate.

We also randomly informed survey recipients about the changes in unemployment insurance under the CARES act. We found that informing employers about the increased generosity of unemployment insurance was associated with lower employment projection in December 2020, among those businesses that were told about the CARES-like loans. Information about unemployment insurance had no impact on the expected probability of remaining open. More work is needed to understand how interactions between programs may influence economic outcomes.

\section{Industry Differences in Response to Crisis Duration}

COVID-19 disruptions do not affect all businesses equally. Some are deemed essential and remain open, while others have been forcibly shut. Some businesses are able to reduce

\footnotetext{
${ }^{6}$ Those who report their intention not to take-up the program due to having sufficient cash have a median of 3.5 months of cash on hand. Those who express other reasons for lack of take-up have a median of 1 month of cash.
} 
contagion among employees through a shift to remote work while other businesses prove illequipped for the transition. For a variety of reasons related to both the underlying nature of the business and management capacity, COVID-19 poses an existential threat to some and not others.

Disparities between businesses appear most stark when we measure their resilience to extended durations of the pandemic. In our survey, we ask the following hypothetical: "We want to understand how the duration of the COVID-19 disruptions might change your answers. Suppose that most COVID-19 disruptions continue for $\mathrm{X}$ months, what is the likelihood of your business remaining operational by Dec. 31, 2020? Please provide your best guess." We randomize the duration to be 1 month, 4 months or 6 months, and offer respondents a 5-point scale ranging from extremely unlikely to extremely likely. As before, we transform this answer into a binary outcome of likely or unlikely to remain open for ease of exposition.

In Table 5 we display the responses to this question by industry. When firms are told to expect a one-month crisis, the expectation of remaining open by the end of the year hovers around 70 percent across all industries with the exception of Arts and Entertainment, and Personal Services. In those industries, the expectation of remaining open drops to 65 and 57 percent respectively.

When firms are told to expect a six-month crisis, the average expectation of remaining open falls to 38 percent, and there is significant heterogeneity between sectors. The expected survival probability for firms in Arts and Entertainment drops precipitously to 45 percent if the crisis lasts 4 months, and 35 percent if the crisis lasts 6 months. The expected probability of being open for Personal Services firms fall to 22 percent if the crisis lasts six months.

The restaurant industry seems particularly vulnerable to a long crisis. Restaurateurs believe that they have a 72 percent chance of survival if the crisis lasts one month, but if the crisis lasts four months, then they give themselves only a 30 percent chance of survival. If the crisis lasts for six months, then they expect to survive with only a 15 percent probability. Likewise, the chance of survival for firms in tourism and lodging drops to 27 percent by the 6month mark. Meanwhile, Banking and Finance, Real Estate and Professional Services say that they will be able to weather extended disruptions far better than these more exposed sectors. 
These results suggest that the damage to our economy and its network of small businesses will be far larger if the crisis lasts for many months. This suggests large economic benefits for policies that can safely lead to reopening the economy quickly.

\section{Conclusion}

Small businesses employ almost fifty percent of American workers. Yet, our results underscore the financial fragility of many small businesses, and how deeply affected they are by the current crisis. In our sample, which is skewed toward retail sales, we found that 43 percent of businesses were temporarily closed and that employment has fallen by 40 percent. This represents a shock to America's small firms that has little parallel since the 1930s. Our results suggest that many of these firms have little cash on hand, which means that they will either have to dramatically cut expenses, take on additional debt, or declare bankruptcy. This highlights the ways in which the immediacy of new funding might impact medium term outcomes.

Small businesses' responses to our survey suggest that many are likely to fail absent assistance. As of the last week in March 2020, 38 of businesses viewed it as unlikely or only somewhat likely that they would be open as of the end of 2020. While optimism increased when they were informed about the CARES loan program, it is unclear whether the CARES act will enable most of America's small businesses to survive - or whether beliefs about its impact are overly optimistic.

The results also highlight the importance of well-designed and sustained economic and public health policy measures. Three policy-relevant results of our survey stand out. First, more than 13 percent of respondents say that they do not expect to take out CARES Act PPP loans because of the application hassle, distrust that the federal government will forgive the loans, or worry about complicated eligibility rules. Streamlining the application process and clarifying the eligibility criterion and loan forgiveness rules might, therefore, increase the take-up right for loans. Second, firms in particularly exposed industries - such as restaurants, tourism, and personal services - project that they will find it extremely difficult to stay in business if the crisis lasts for longer than four months. These suggest large economic benefits from any policies that can safely shorten the economic shutdown (e.g. through stronger short-term containment policies). Third, if we extrapolate the 72 percent of businesses who indicate they would take up the CARES PPP loans to all US small businesses and assume that all businesses take out the 
maximum loan size (2.5 months of expenses), the total volume of loans would be approximately $\$ 410$ billion, somewhat beyond the $\$ 349$ billion allocated in the CARES act right now. ${ }^{7}$

\section{References}

Barro, R. J., J. F. Ursúa, and J. Weng (2020, March). The coronavirus and the great influenza pandemic: Lessons from the "Spanish flu" for the coronavirus's potential effects on mortality and economic activity. Working Paper 26866, National Bureau of Economic Research.

Bazerman, Max and Donald Moore (1994). “Judgment in Managerial Decision Making” Wiley Publishing.

Bloom, N., Eifert, B., Mahajan, A., McKenzie, D., \& Roberts, J. (2013). Does management matter? Evidence from India. The Quarterly Journal of Economics, 128(1), 1-51.

Garrett, T. A. (2007). Economic Effects of the 1918 Influenza Pandemic: Implications for a Modern-Day Pandemic. Federal Reserve Bank of St. Louis.

Garrett, T. A. (2008). Pandemic economics: the 1918 influenza and its modern-day implications. Review 90(Mar), 74-94.

Parsa, H. G., Self, J. T., Njite D., and King, T. (2005) Why restaurants fail. Cornell Hotel and Restaurant Administration Quarterly, 46(3), 304-322.

Appendix

Appendix 1: Initial message shown to respondents

Thank you in advance for your participation in our survey!

Academics from Harvard University and the University of Chicago are looking to better understand the impact the coronavirus is having on the local business ecosystem - and what can be done to help local businesses. We hope that it will help to communicate your current needs to policymakers.

Please share your truthful and considered views. Your individual answers will be completely confidential.

Sincerely,

Zoe Cullen and Chris Stanton

Professors of Business Administration

Harvard Business School

\footnotetext{
${ }^{7}$ Monthly payroll in the 2017 Census data for businesses under 500 employees totaled 226 billion dollars.
} 
Tables and Figures

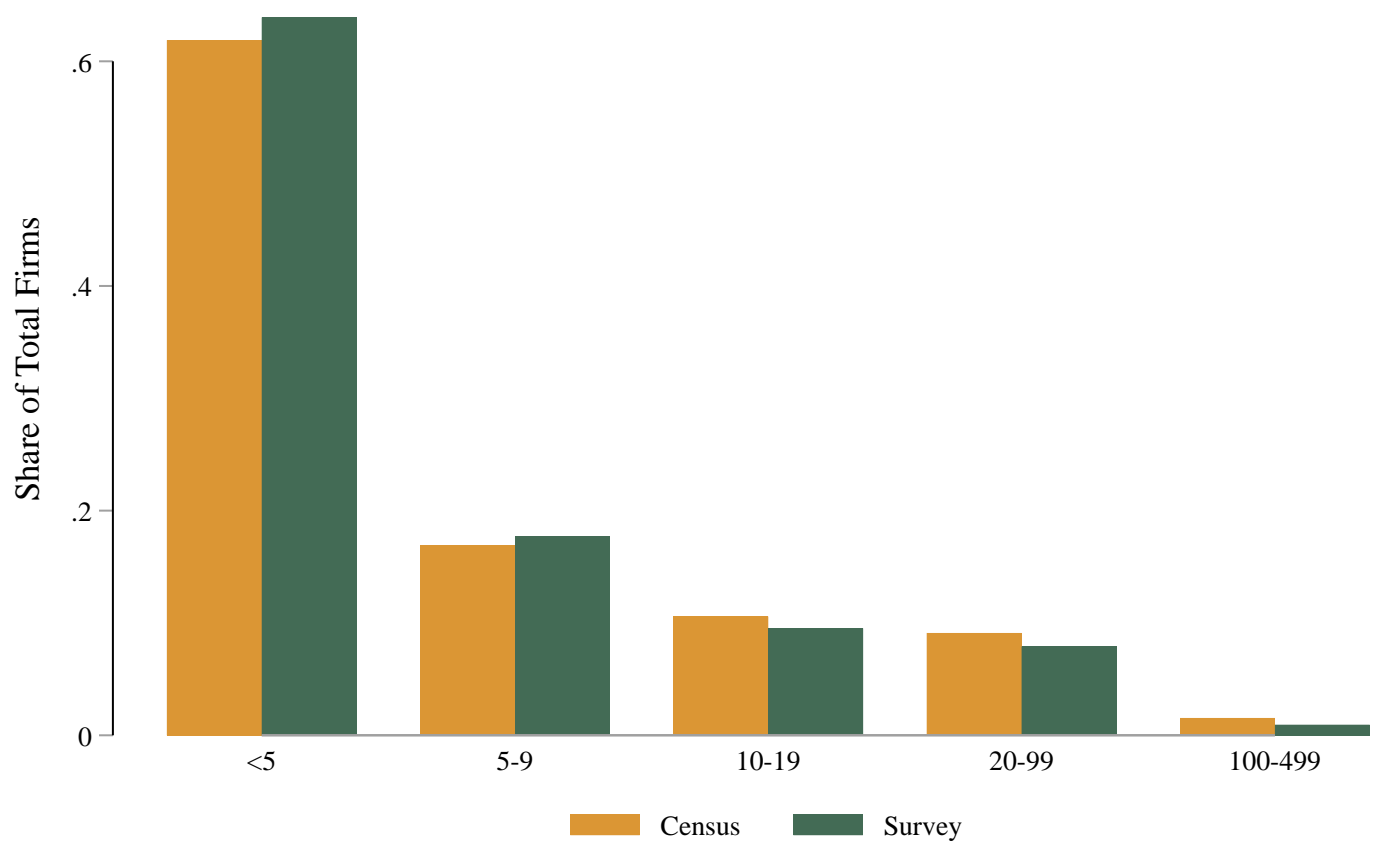

Sample size is 4865 and does not include 954 responses with missing employment data.

Figure 1: Firm Size in the Survey And Census

This figure plots the share of firms in each employment category for the 2017 Census of US Businesses and the survey respondents. 


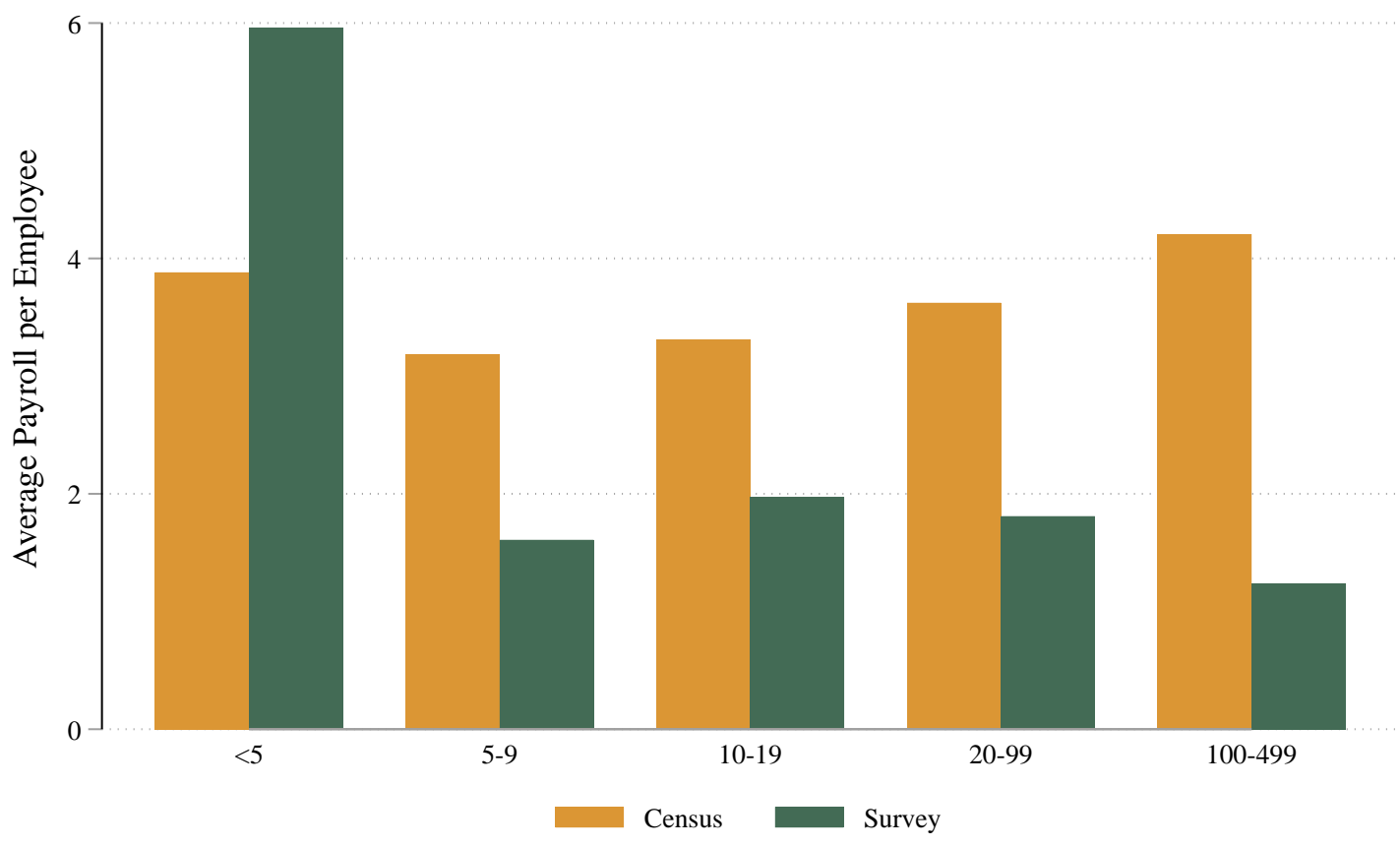

Sample size is 4865 and does not include 954 responses with missing employment data.

Figure 2: Average Per Capita Payroll (\$ 1000s) in the Survey and Census

This figure plots per-employee payroll in thousands of dollars by firm size for the 2017 Census of US Businesses aggregates and the survey respondents. The Census data only reports annual payroll for W2 workers and the number of firms in a cell. To calculate payroll for the survey firms, we take the midpoint of categorical answers for monthly expenses, multiply by the fraction of expenses going toward payroll and divided by total employees (we cannot distinguish between W2 employees and contractors). 


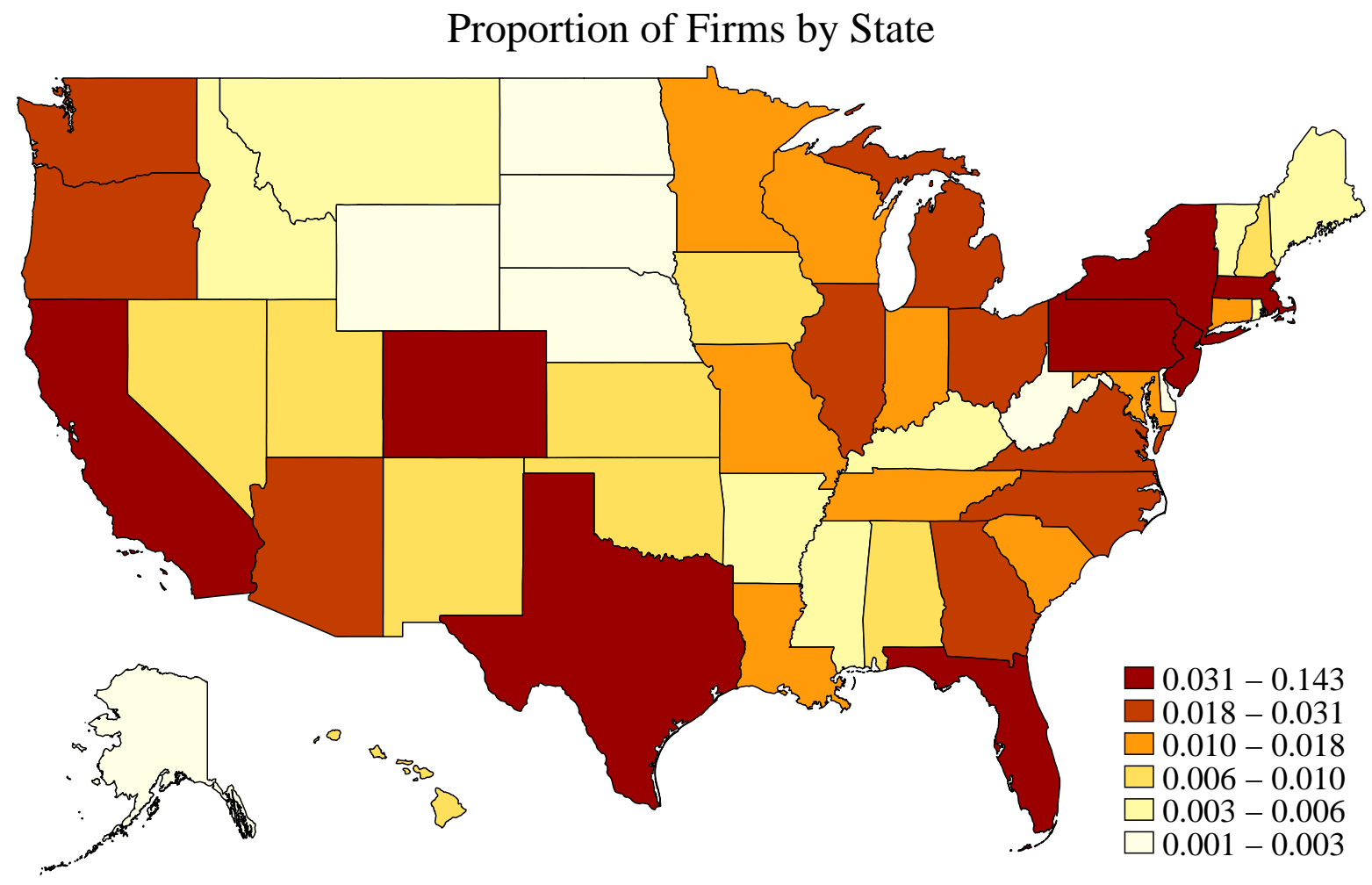

Figure 3: Coverage by State

This figure plots shares of survey responses across different states. 


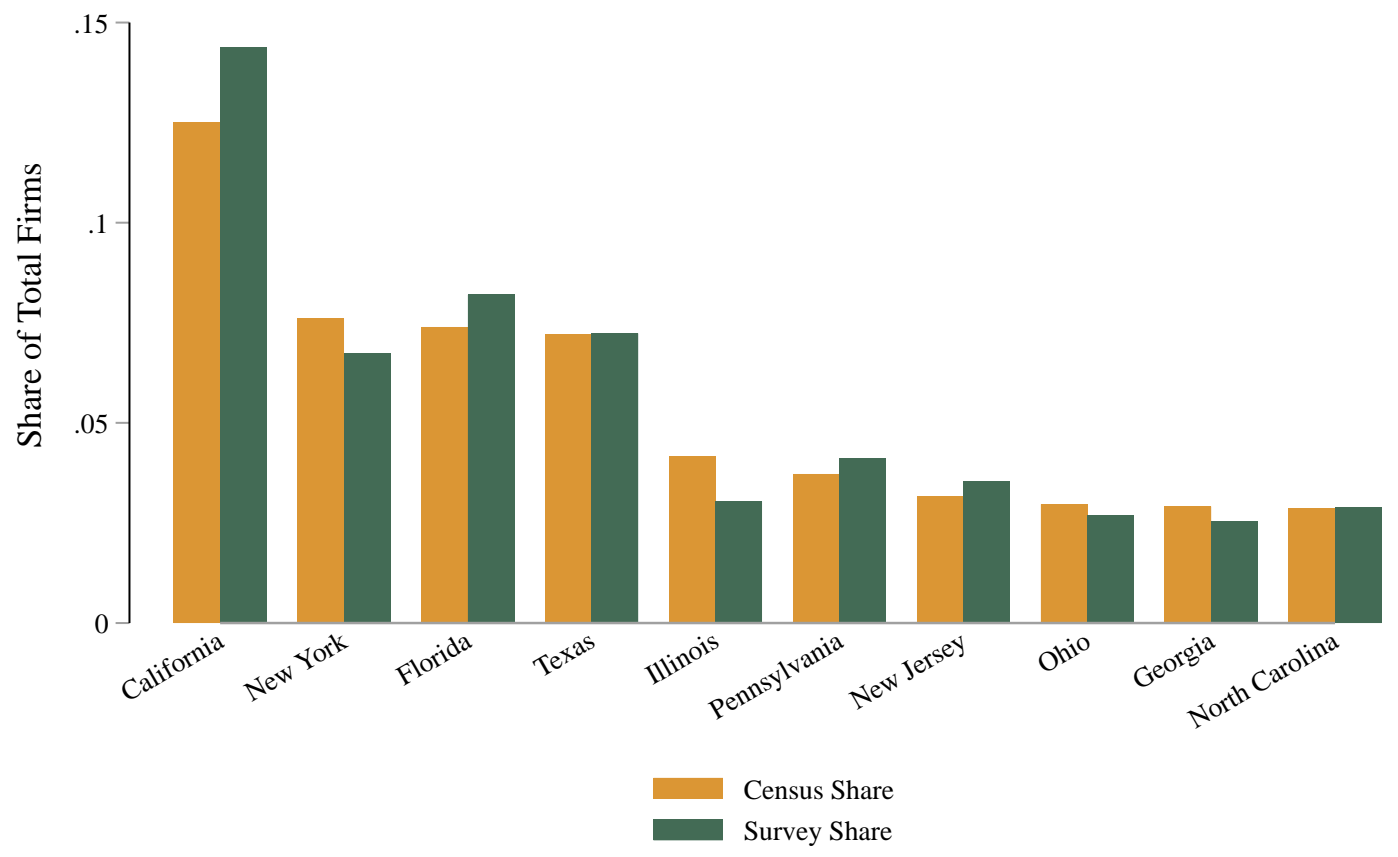

Omits responses with missing location data.

Figure 4: Firm Size in the Survey and Census

This figure plots the share of firms in each state for the 2017 Census of US Businesses and the survey respondents. 
Histogram of Approximate Months of Cash Available

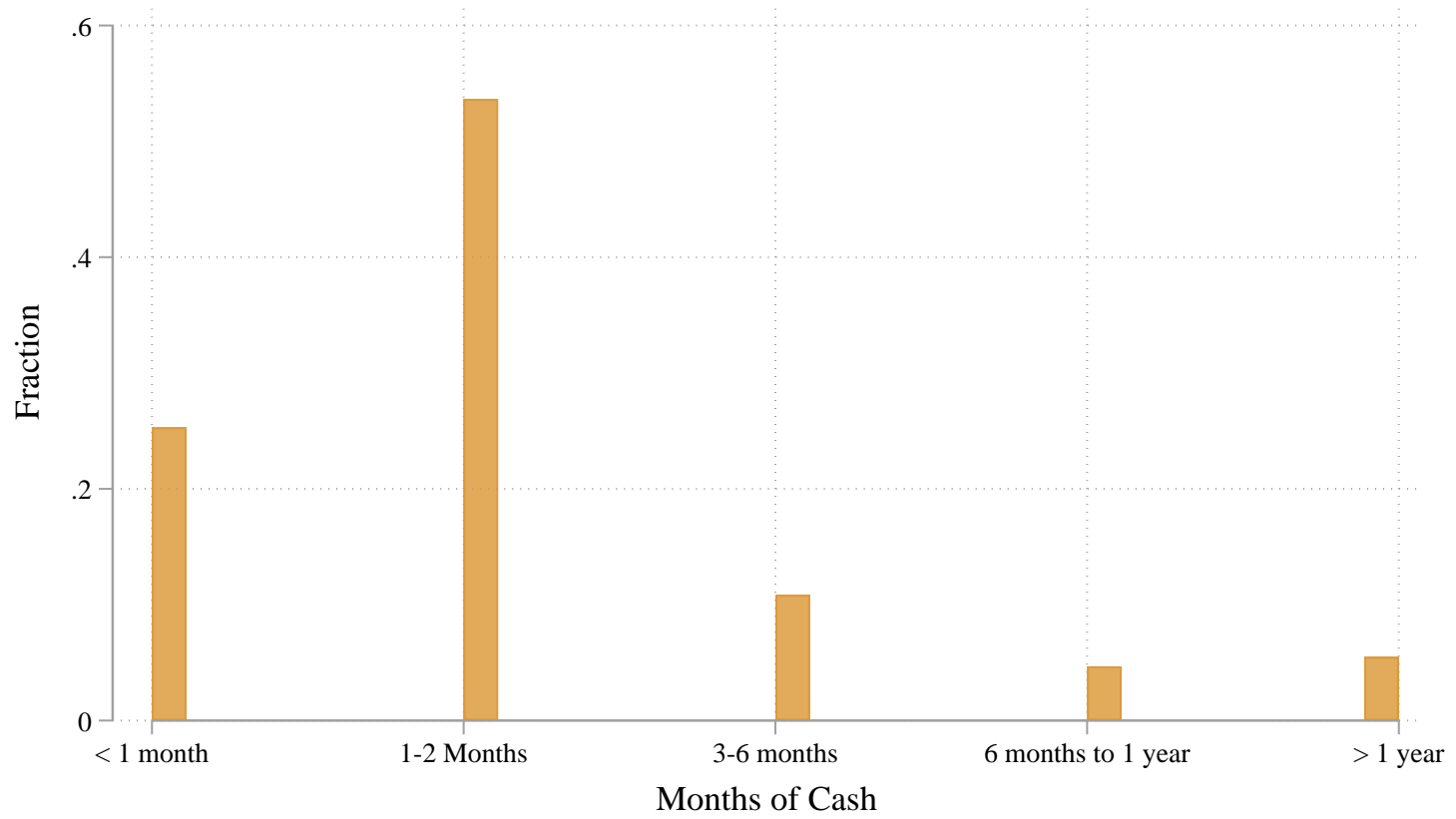

$\mathrm{N}=4184$

Figure 5: MONTHS OF CASH

This figure plots firms' months of cash available as a multiple of January 2020 expenses. We compute this measure by taking the midpoint of categorical responses for the amount of cash on hand and divide by the midpoint of the categorical response for typical monthly expenses prior to the crisis. 


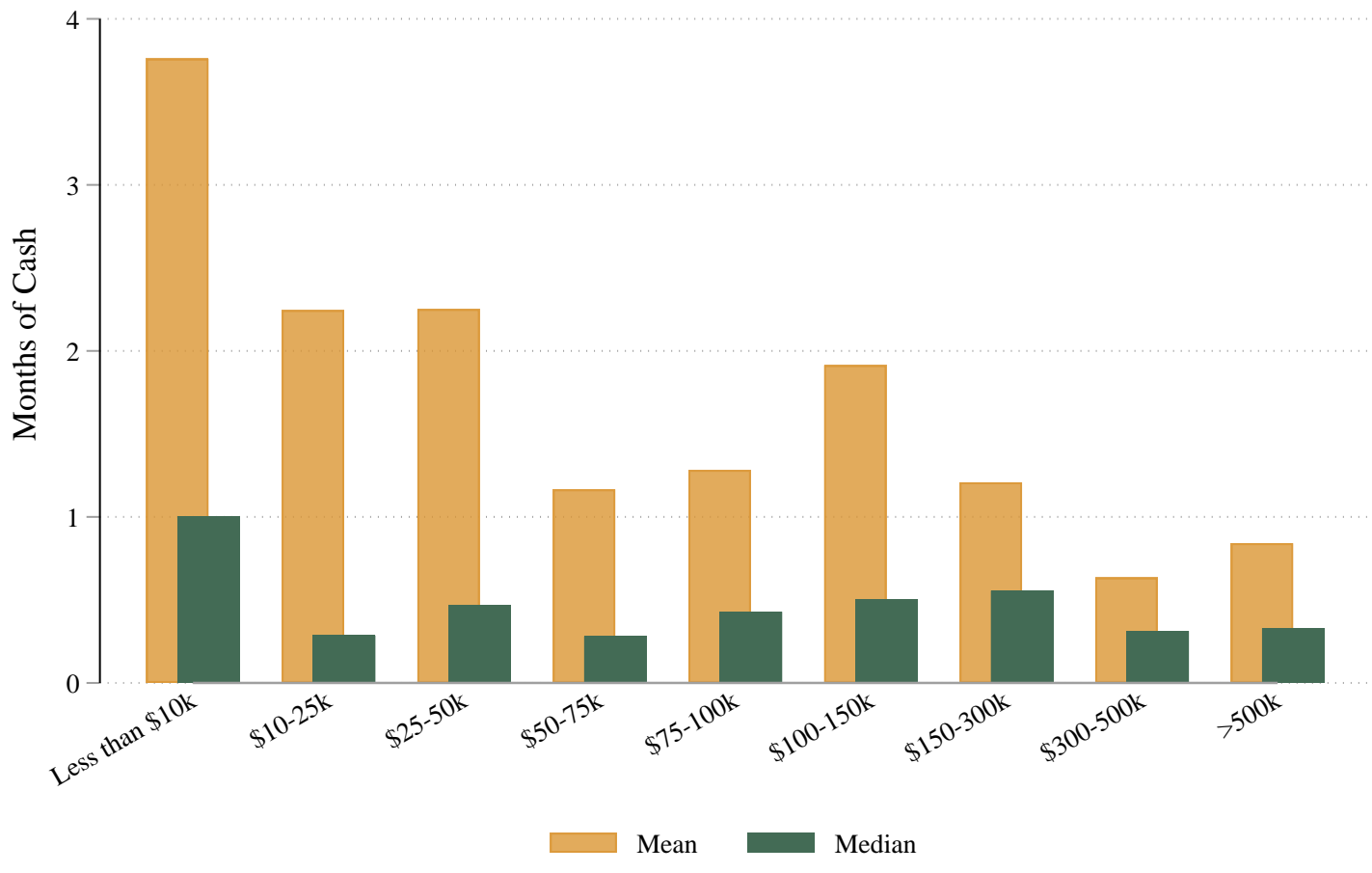

Figure 6: Mean and Median Months of Cash Split by Monthly Expenses $\$ 000$ s

This figure plots means and medians of the months of cash available measure across the distribution of typical monthly expenses. 


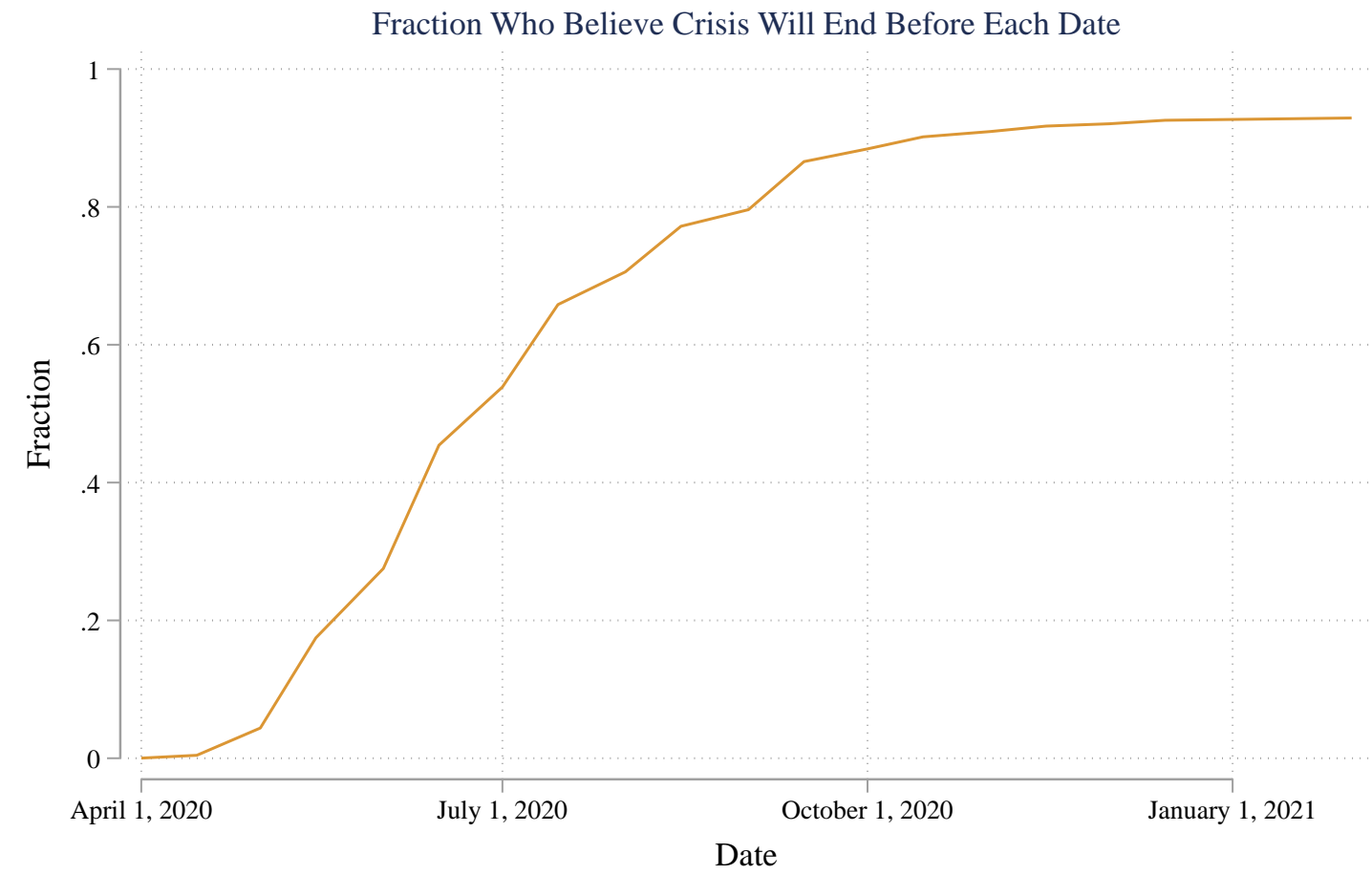

Figure 7: CDF of Expected COVID End Date

This figure plots the distribution function across respondents for the expected end date of COVID related disruptions . 
Likelihood of Being Open on Dec 31, 2020

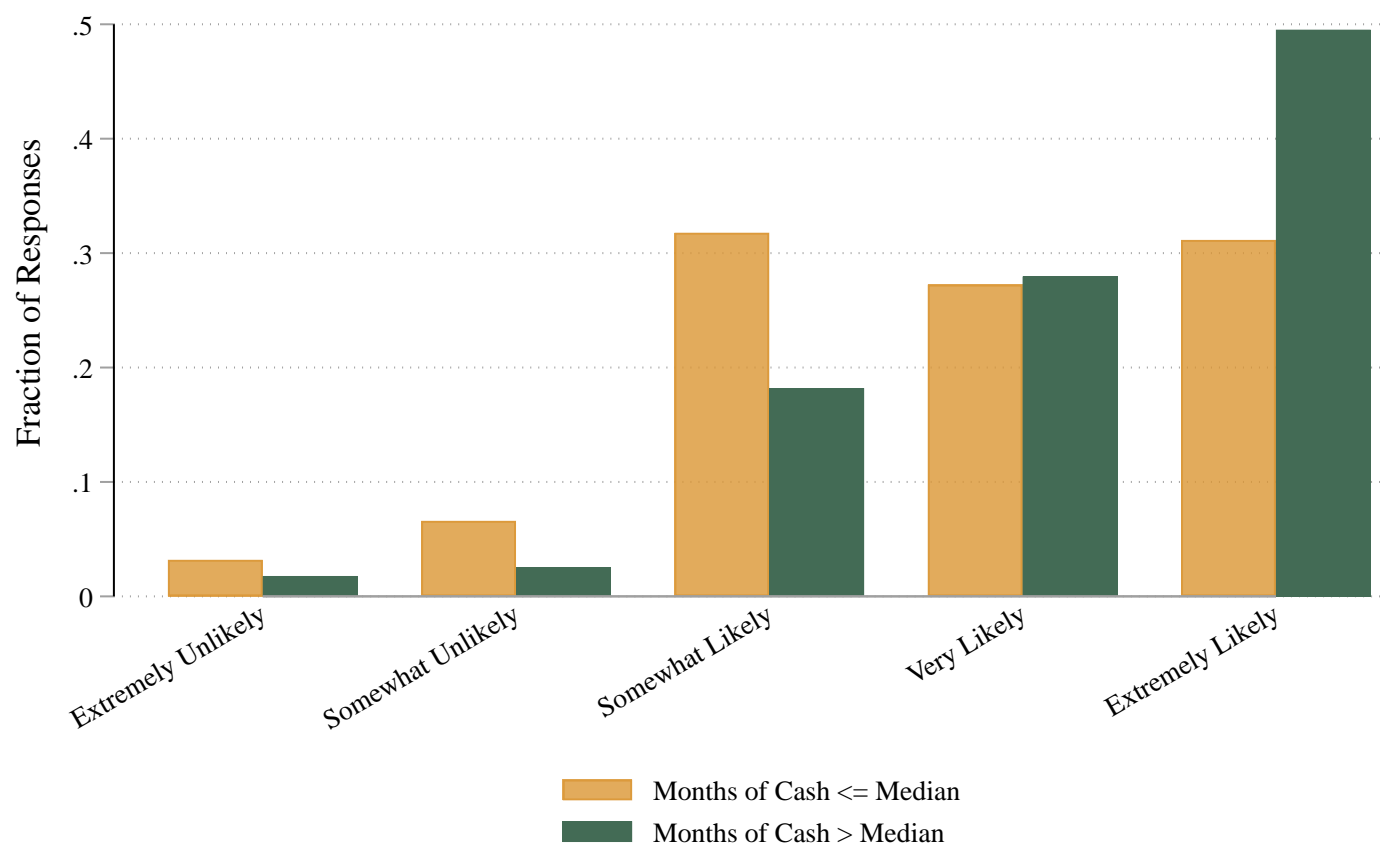

Figure 8: Likelihood of Remaining Open or Re-Opening by December

This figure displays the frequency of answers to a question about the likelihood of being open in December, 2020. Responses are split by whether firms have above median cash on hand relative to typical expenses.. 


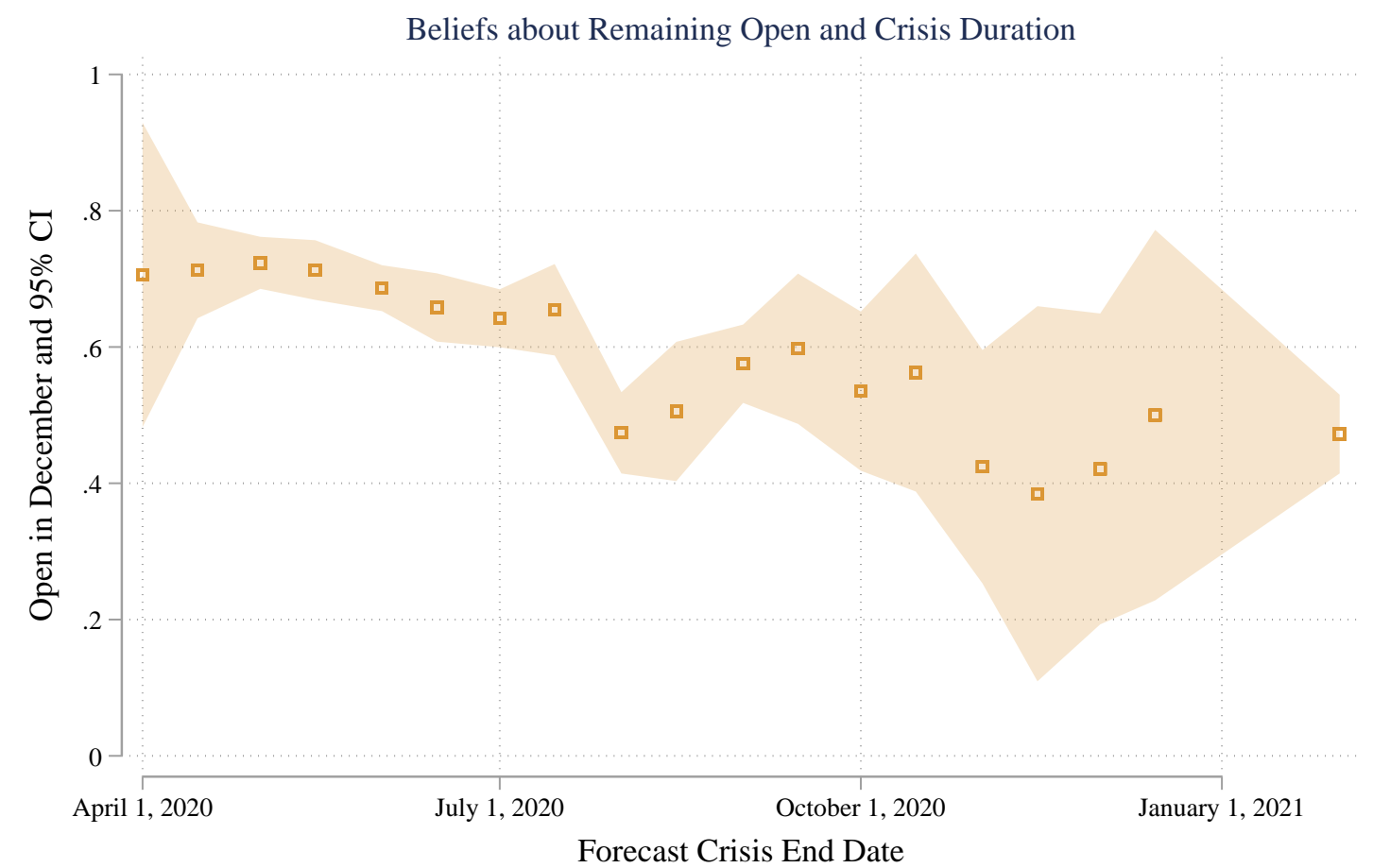

Figure 9: Likelihood of Remaining Open or Re-Opening by December, 2020 as a FuncTION of Beliefs ABout COVID End DATE

This figure plots the likelihood of being open in December, 2020 as a function of respondents' expected COVID end date. Averages are plotted and the shaded region is the confidence interval. The opening likelihood is computed as the share of respondents who answered "Extremely likely" or "Very likely." 


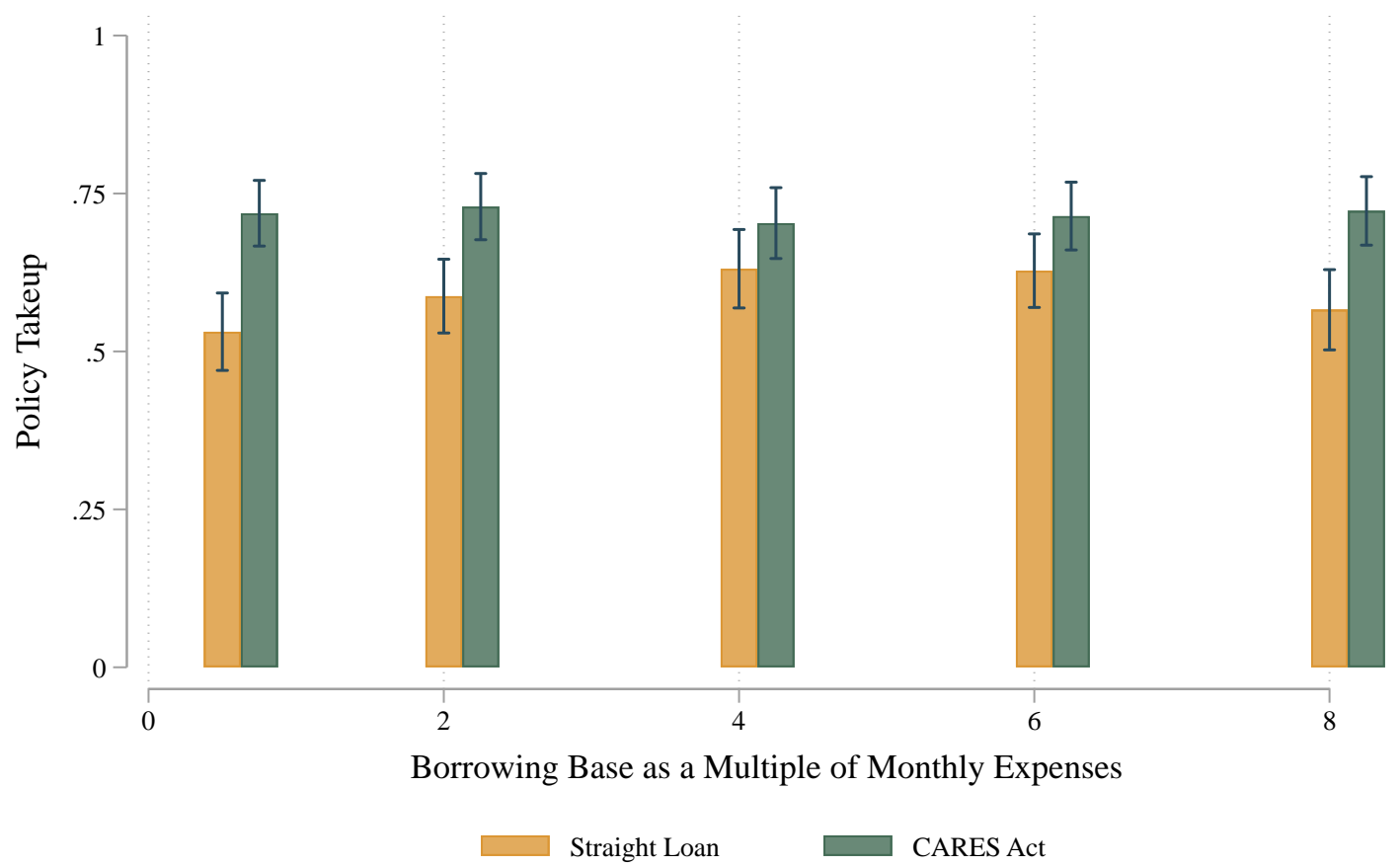

Sample size is 2621 and pooled t-stat on difference between policies is 6.99 .

Figure 10: Differences in Policy Take-up Across Loans versus CARES Act PPP Program Split by Hypothetical Limits on Borrowing Amount

This figure displays policy take-up rates for loans versus the stylized Paycheck Protection Program policy using a between subjects design. The borrowing base was also randomized between subjects as a multiple of typical monthly expenses prior to the crisis. The text displayed for the PPP program was: "Imagine a policy where the government allows you to borrow up to [borrowing base] times your typical monthly expenses without posting any collateral. You could use this money to cover any of your business expenses. The loan will be forgiven by the amount spent on payroll, lease, rent, mortgage, and utility payments in the 8 weeks after origination (you can consider this amount to be a grant). The remainder of the loan (that is not spent on these items) will have deferred payments for 1 year. After that, the loan would have an annual interest rate of $4 \%$ (deferred for 1 year) and you would have up to 10 years to repay the loan. For example, if you borrow $\$ 50,000$ and you have no qualifying expenses to offset the loan, the required monthly payment starting 1 year from today would be $\$ 506$ per month for 10 years. If you borrow $\$ 50,000$ and spend $\$ 40,000$ to pay your employees during the first 8 weeks, you will have 10 years to pay the remaining $\$ 10,000$ with monthly payments of $\$ 102$." Subjects in the loan condition saw the text: "Imagine the government offers a loan allowing you to borrow up to [borrowing base] times your typical monthly expenses without posting any collateral. You could use this money to cover any of your business expenses. The loan would have an annual interest rate equivalent of $4 \%$ and principal and interest payments would be deferred for 1 year. You would have up to 10 years to repay the loan. For example, if you borrow $\$ 50,000$, the required monthly payment starting 1 year from today would be $\$ 506$ per month for 10 years." Pooled means for the loan and CARES act are 0.59 and 0.72 , respectively. 


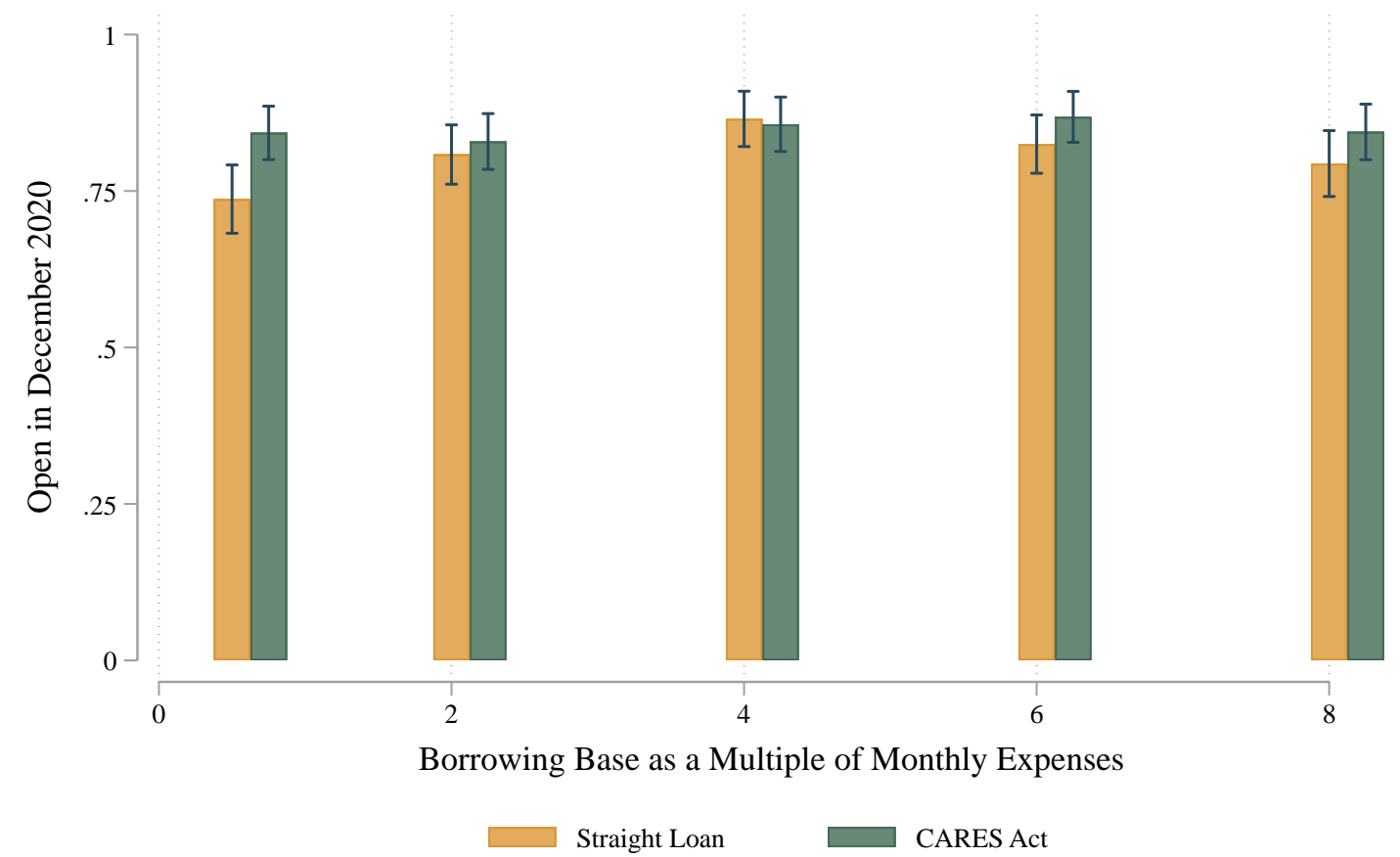

Sample size is 2561 and pooled t-stat on difference between policies is 2.86 .

Figure 11: Differences in Policy Effects on the Propensity to Remain Open in DeCember of 2020, Split By Hypothetical Limits on Borrowing Amount

This figure plots differences in the propensity to remain open under different policies. The measure is computed using a follow-up question after policy information displayed, using the fraction that chose "Very likely" or "Extremely likely" to be open in December of 2020. See notes for Figure 10 for additional detail about the policy display. Pooled means for the loan and CARES act are 0.805 and 0.848 , respectively. 


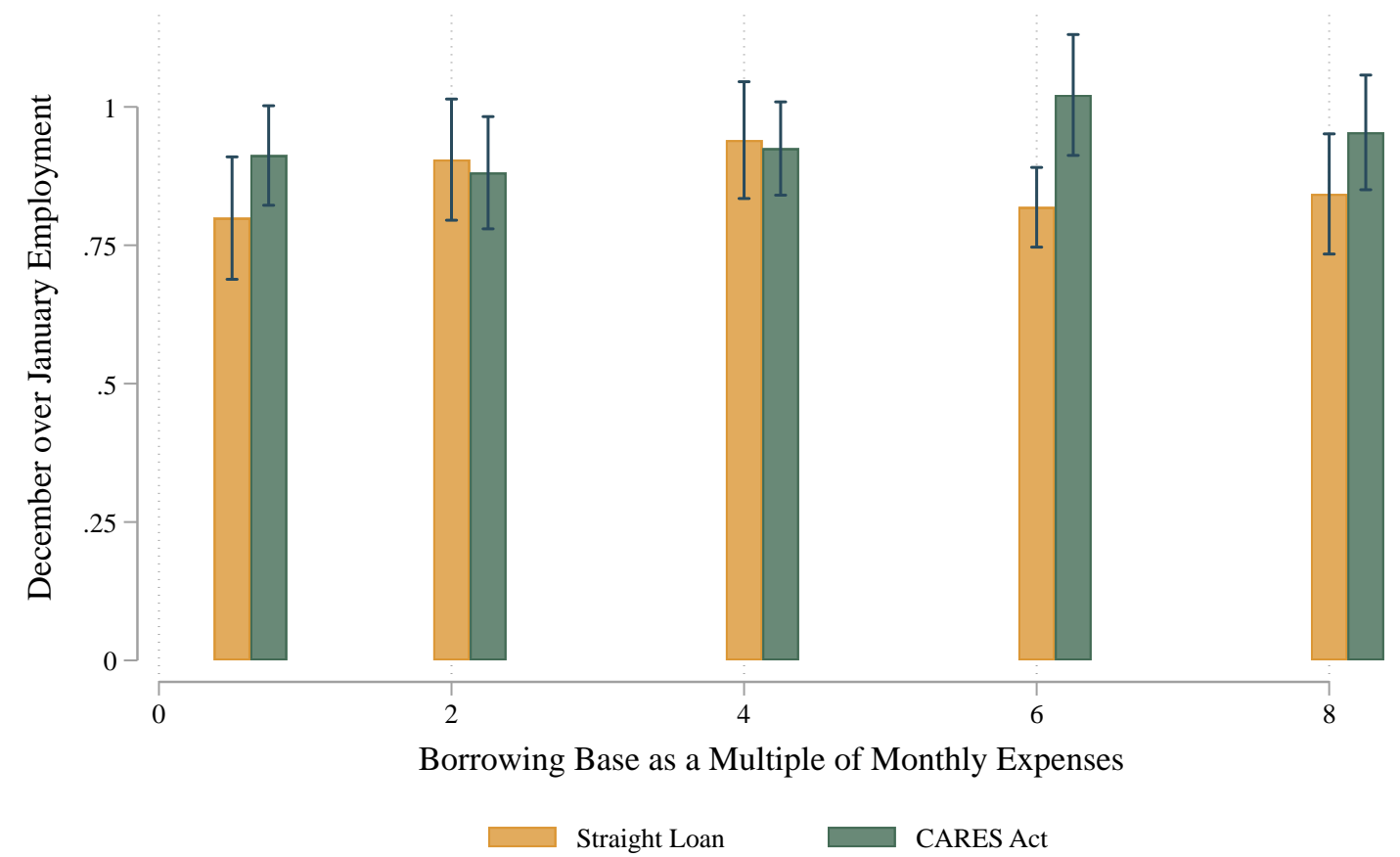

Sample size is 2350 and pooled t-stat on difference between policies is 2.43 .

Figure 12: Differences in Policy Effects on Relative Employment Between December AND JANUARY

This figure plots differences in the ratio of relative employment between December 2020 and January 2020 under different policies. The December 2020 employment measure is computed using a follow-up question after policy information displayed. See notes for Figure 10 for additional detail about the policy display. Pooled means for the loan and CARES act are 0.86 and 0.94, respectively. 


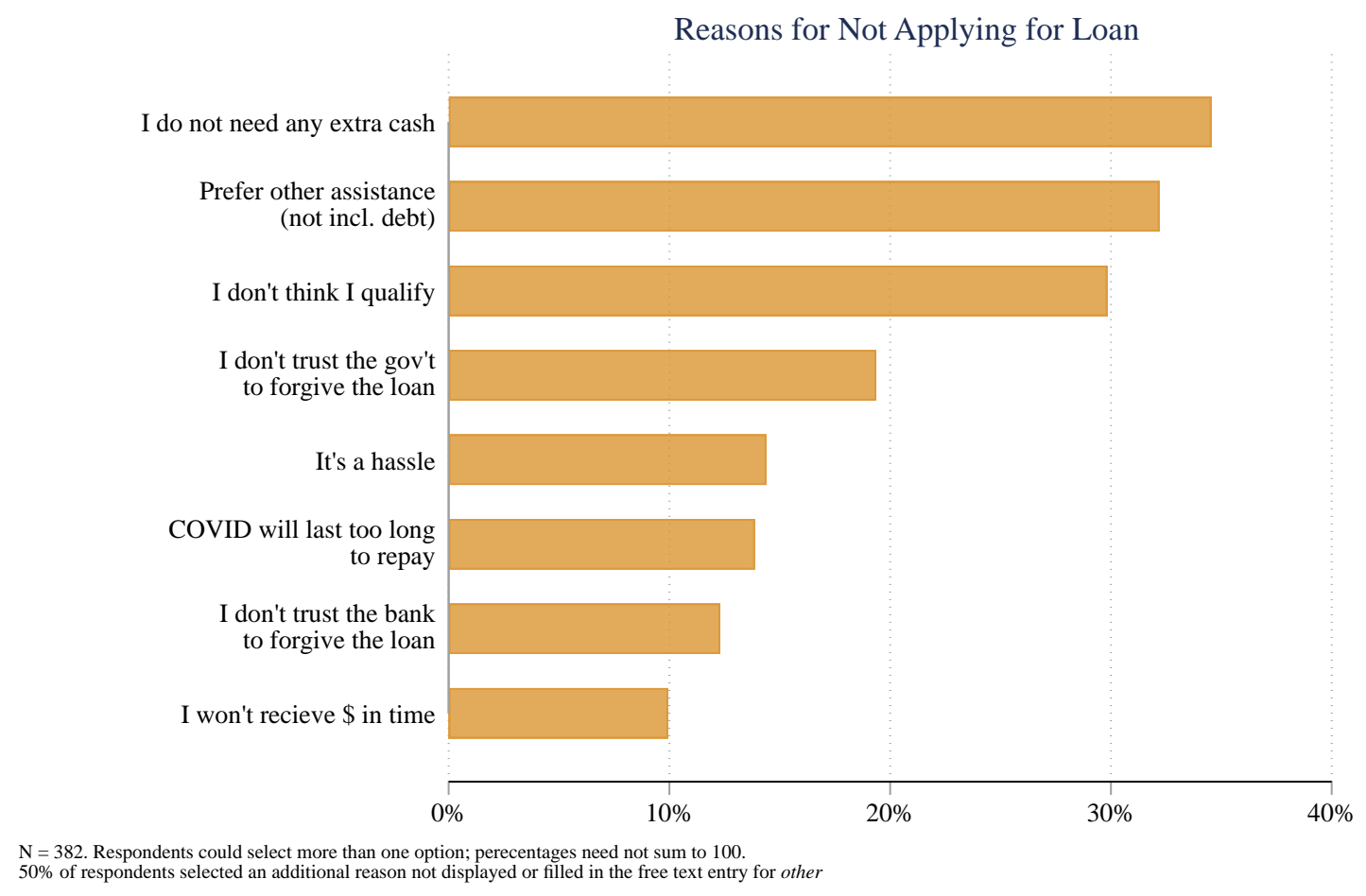

Figure 13: Reasons For Not Using the Resources in the Senate Bill

This figure contains the frequency of responses for reasons that respondents would not take-up aid under the CARES Act policy condition. 383 respondents indicated they would not use the policy and 382 answered this question. 
Table 1: Summary Measures Across Regions

\begin{tabular}{|c|c|c|c|c|c|c|c|c|}
\hline & \multicolumn{2}{|c|}{$\begin{array}{l}\text { Currently } \\
\text { Closed }\end{array}$} & \multicolumn{2}{|c|}{$\begin{array}{l}\text { Exp Closed } \\
\text { December }\end{array}$} & \multicolumn{2}{|c|}{$\begin{array}{c}\text { Weeks COVID } \\
\text { Will Last }\end{array}$} & \multicolumn{2}{|c|}{$\begin{array}{l}\text { Current v Jan } \\
\text { Employment }\end{array}$} \\
\hline & Mean & $\mathrm{SD}$ & Mean & SD & Mean & $\mathrm{SD}$ & Mean & $\mathrm{SD}$ \\
\hline East North Central & .449 & .498 & .353 & .478 & 14.7 & 10.2 & .68 & .38 \\
\hline East South Central & .414 & .494 & .368 & .484 & 16.1 & 11.4 & .57 & .49 \\
\hline Mid Atlantic & .541 & .499 & .372 & .484 & 14.6 & 10.03 & .53 & .45 \\
\hline Mountain & .388 & .488 & .348 & .477 & 16 & 11.34 & .68 & .38 \\
\hline New England & .473 & .5 & .325 & .469 & 16.6 & 10.19 & .55 & .49 \\
\hline South Atlantic & .455 & .498 & .371 & .483 & 15.4 & 10.7 & .55 & .48 \\
\hline Pacific & .413 & .493 & .378 & .485 & 15.5 & 10.33 & .63 & .45 \\
\hline West North Central & .43 & .496 & .349 & .478 & 15.7 & 10.84 & .66 & .41 \\
\hline West South Central & .404 & .491 & .389 & .488 & 15.1 & 11.06 & .68 & .43 \\
\hline Total & .446 & .497 & .366 & .482 & 15.38 & 10.57 & .6 & .45 \\
\hline Populated Obs. & 4969 & . & 4069 & . & 4170 & . & 4362 & . \\
\hline
\end{tabular}

Notes. This table reports breakdowns by regions. There are 16 observations with unknown region. Note that the Currently Closed column includes both temporary and permanent closures. The measure Exp Closed December comes from a question asking about the likelihood of being open in December and closure is based off a binary indicator for those marking "Extremely Unlikely," "Somewhat Unlikely," or "Somewhat Likely." The current versus January employment ratios are weighted by January employment. 
Table 2: Summary Measures by Firm Size

\begin{tabular}{lcccccccc}
\hline \hline & \multicolumn{2}{c}{ Currently } & \multicolumn{2}{c}{ Exp Closed } & \multicolumn{2}{c}{ Weeks COVID } & \multicolumn{2}{c}{ Current v Jan } \\
& Closed & \multicolumn{2}{c}{ December } & \multicolumn{2}{c}{ Will Last } & \multicolumn{2}{c}{ Employment } \\
& Mean & SD & Mean & SD & Mean & SD & Mean & SD \\
\hline Under 5 & .459 & .498 & .356 & .479 & 15.8 & 10.86 & .66 & .49 \\
$5-9$ & .47 & .499 & .393 & .489 & 14.7 & 10.2 & .52 & .45 \\
$10-19$ & .41 & .492 & .414 & .493 & 14.7 & 10.05 & .55 & .47 \\
$20-99$ & .364 & .482 & .302 & .46 & 14.1 & 9.48 & .58 & .42 \\
$100-499$ & .261 & .444 & .222 & .424 & 16.2 & 10.8 & .72 & .44 \\
Unknown & .413 & .495 & .494 & .503 & 16.7 & 10.41 &. &. \\
\hline Total & .446 & .497 & .366 & .482 & 15.38 & 10.57 & .6 & .45 \\
$\mathrm{~N}$ & 4969 &. & 4069 &. & 4170 &. & 4362 &. \\
\hline \hline
\end{tabular}

Notes. This table reports breakdowns by firm size. Note that the Currently Closed column includes both temporary and permanent closures. The measure Exp Closed December comes from a question asking about the likelihood of being open in December and closure is based off a binary indicator for those marking "Extremely Unlikely," "Somewhat Unlikely," or "Somewhat Likely." The current versus January employment ratios are weighted by January employment. 
Table 3: Summary Measures by Industry

\begin{tabular}{lcccccccc}
\hline \hline & \multicolumn{2}{c}{ Currently } & \multicolumn{2}{c}{ Exp Closed } & \multicolumn{2}{c}{ Weeks COVID } & \multicolumn{2}{c}{ Current v Jan } \\
& Closed & \multicolumn{2}{c}{ December } & \multicolumn{2}{c}{ Will Last } & \multicolumn{2}{c}{ Employment } \\
& Mean & SD & Mean & SD & Mean & SD & Mean & SD \\
\hline All Retailers, except Grocery & .522 & .5 & .441 & .497 & 14.1 & 9.59 & .5 & .42 \\
Arts and entertainment & .713 & .453 & .423 & .495 & 17.3 & 11.12 & .4 & .46 \\
Banking/finance & .192 & .395 & .25 & .434 & 16 & 10.88 & .79 & .35 \\
Construction and related & .324 & .468 & .383 & .487 & 14.3 & 10.23 & .66 & .4 \\
Health care and related & .445 & .498 & .29 & .454 & 15 & 10.4 & .69 & .37 \\
Other & .397 & .489 & .349 & .477 & 16.6 & 11.16 & .7 & .41 \\
Personal Services & .86 & .348 & .387 & .488 & 11.7 & 8.24 & .35 & .4 \\
Professional Services & .218 & .413 & .292 & .456 & 15.7 & 10.55 & .79 & .41 \\
Real Estate & .381 & .487 & .302 & .461 & 15.6 & 11.31 & .68 & .42 \\
Restaurants and related & .543 & .5 & .536 & .5 & 13.3 & 9.03 & .25 & .37 \\
Tourism/Lodging & .615 & .488 & .442 & .498 & 16 & 9.83 & .3 & .34 \\
Total & .446 & .497 & .366 & .482 & 15.38 & 10.57 & .6 & .45 \\
N & 4969 &. & 4069 &. & 4170 &. & 4362 &. \\
\hline \hline
\end{tabular}

Notes. This table reports breakdowns by industry. There are 16 observations with unknown region. Note that the Currently Closed column includes both temporary and permanent closures. The measure Exp Closed December comes from a question asking about the likelihood of being open in December and closure is based off a binary indicator for those marking "Extremely Unlikely," "Somewhat Unlikely," or "Somewhat Likely." The current versus January employment ratios are weighted by January employment. 
Table 4: Breakdown of Issues Affecting Businesses

\begin{tabular}{lccccc}
\hline Business status & N total & N answering & Supply Chain & Employee Health & Demand/Orders \\
\hline Currently open & 2,752 & 2,198 & 30.29 & 49.82 & 66.16 \\
Temp. closed & 2,117 & 1,783 & 35.58 & 59.83 & 83.31 \\
Perm. closed & 100 & 85 & 37.87 & 60.85 & 86.13 \\
Total & 4,969 & 4,066 & 34.58 & 56.83 & 78.53 \\
\hline
\end{tabular}

Notes. This table reports respondents' reactions to the importance of issues affecting their business, broken down by the status of the business at the time of taking the survey. 
Table 5: Reported Likelihood of Remaining Open by Industry and Hypothetical Crisis DURATION

\begin{tabular}{lcccc}
\hline \hline Industry & $\mathrm{N}$ & 1 Month & 4 Months & 6 Months \\
\hline All Retailers, except Grocery & 598 & 0.69 & 0.35 & 0.33 \\
Arts and entertainment & 314 & 0.65 & 0.45 & 0.35 \\
Banking/finance & 177 & 0.78 & 0.63 & 0.59 \\
Construction & 448 & 0.72 & 0.43 & 0.45 \\
Health care & 449 & 0.79 & 0.47 & 0.35 \\
Other & 1,462 & 0.76 & 0.48 & 0.38 \\
Personal Services & 214 & 0.57 & 0.40 & 0.22 \\
Professional Services & 271 & 0.79 & 0.63 & 0.54 \\
Real Estate & 147 & 0.74 & 0.56 & 0.56 \\
Restaurant/Bar/Catering & 173 & 0.72 & 0.30 & 0.15 \\
Tourism/Lodging & 174 & 0.66 & 0.48 & 0.27 \\
Total & 4,427 & 0.72 & 0.47 & 0.38 \\
\hline \hline
\end{tabular}

Notes. This table reports results across industries of expectations of remaining open in December based on different hypothetical durations of the COVID crisis. This question was asked at the end of the survey, after policy questions were conducted. The randomization is between subject. 
Table A1: Census Industry versus Survey Industry Breakdown

\begin{tabular}{lcc}
\hline \hline Industry & Census Percentage & Survey Percentage \\
\hline Agriculture, Forestry, Fishing and Hunting & 0.4 & 1.3 \\
Mining, Quarrying, and Oil and Gas Extraction & 0.3 & 0 \\
Utilities & 0.1 & 0 \\
Construction & 11.7 & 13.2 \\
Manufacturing & 4.1 & 3.1 \\
Wholesale and Retail Trade & 15.7 & 18.5 \\
Transportation and Warehousing & 3.1 & 2.7 \\
Information & 1.3 & 2.8 \\
Finance and Insurance & 4 & 5.2 \\
Real Estate and Rental and Leasing & 5.2 & 4.2 \\
Professional, Scientific, and Technical Services & 13.5 & 7.7 \\
Management of Companies and Enterprises & 0.3 & 0 \\
Administrative and Support and Waste Remediation Svcs & 5.8 & 1.4 \\
Educational Services & 1.5 & 2.3 \\
Health Care and Social Assistance & 10.9 & 13.3 \\
Arts, Entertainment, and Recreation & 2.2 & 9 \\
Accommodation and Food Services & 9 & 8.3 \\
Other Services (except Public Administration) & 11.6 & 7.1 \\
\hline \hline
\end{tabular}

Notes. This table reports results of Census and Survey shares by industry for firms with fewer than 500 employees. Survey response shares are conditional on being able to classify industries, with unavailable or "Other" industry classifications omitted from the denominator. We combine wholesale and retail trade due to the difficulty in separating these out in the survey. 